OPEN ACCESS

Edited by:

Vered Padler-Karavani,

Tel Aviv University, Israel

Reviewed by:

Amanda L. Lewis,

Washington University in St. Louis,

United States

Yaqing Qie,

Mayo Clinic Florida, United States

Paul Crocker,

University of Dundee, United Kingdom

*Correspondence:

Pascal Gagneux

pgagneux@ucsd.edu

Specialty section: This article was submitted to Nutritional Immunology, a section of the journal

Frontiers in Immunology

Received: 13 January 2019 Accepted: 25 March 2019

Published: 30 April 2019

Citation:

Altman MO and Gagneux P (2019) Absence of Neu5Gc and Presence of

Anti-Neu5Gc Antibodies in

Humans - An Evolutionary

Perspective. Front. Immunol. 10:789.

doi: 10.3389/fimmu.2019.00789

\section{Absence of Neu5Gc and Presence of Anti-Neu5Gc Antibodies in Humans - An Evolutionary Perspective}

\author{
Meghan O. Altman ${ }^{1}$ and Pascal Gagneux ${ }^{1,2 *}$ \\ ${ }^{1}$ Department of Pathology, Biomedical Research and Training Facility 2, Glycobiology Research and Training Center, \\ University of California, San Diego, La Jolla, CA, United States, ${ }^{2}$ Department of Anthropology, University of California, San \\ Diego, La Jolla, CA, United States
}

The glycocalyx of human cells differs from that of many other mammals by the lack of the sialic acid N-glycolylneuraminic acid (Neu5Gc) and increased abundance of its precursor $\mathrm{N}$-acetylneuraminic acid (Neu5Ac). Most humans also have circulating antibodies specifically targeting the non-human sialic acid Neu5Gc. Recently, several additional mammalian species have been found to also lack Neu5Gc. In all cases, loss-of-function mutations in the gene encoding the sialic acid-modifying enzyme $\mathrm{CMAH}$ are responsible for the drastic change in these species. Unlike other glycan antigens, Neu5Gc apparently cannot be produced by microbes, raising the question about the origin of these antibodies in humans. Dietary exposure and presentation on bacteria coating themselves with Neu5Gc from the diet are distinct possibilities. However, the majority of the non-human species that lack Neu5Gc do not consume diets rich in Neu5Gc, making it unlikely that they will have been immunized against this sialic acid. A notable exception are mustelids (ferrets, martens and their relatives) known for preying on various small mammal species rich in Neu5Gc. No studies exist on levels of anti-Neu5Gc antibodies in non-human species. Evolutionary scenarios for the repeated, independent fixation of CMAH loss-of-function mutations at various time points in the past include strong selection by parasites, especially enveloped viruses, stochastic effects of genetic drift, and directional selection via female immunity to paternal Neu5Gc. Convergent evolution of losses of the vertebrate-specific self-glycan Neu5Gc are puzzling and may represent a prominent way in which glycans become agents of evolutionary change in their own right. Such change may include the reconfiguration of innate immune lectins that use self-sialic acids as recognition patterns.

Keywords: sialic acid, Neu5Gc, Neu5Ac, xenoglycan, anti-glycan antibodies, xeno-antigen

\section{INTRODUCTION}

The glycocalyx of all vertebrate cells is decorated with abundant terminal sialic acids. These acidic nine-carbon backbone sugars cap the ends of tens to hundreds of millions of glycan chains per cell. In mammalian species and other vertebrates, the sialic acids $N$-acetylneuraminic acid (Neu5Ac) and its derivative $\mathrm{N}$-glycolylneuraminic acid (Neu5Gc) are the two most common forms, each a 
family of molecules with various modifications of the canonical, 9-carbon monosaccharide (1). Until recently, humans were the only mammalian species known to lack the sialic acid Neu5Gc, as our lineage fixed the loss-of-function mutation affecting the single copy $C M A H$ gene that encodes the sialic acid-modifying enzyme CMAH over 2 million years ago in the lineage leading to $H$. sapiens $(2,3)$. More recently, several other species of mammals have been documented to also lack Neu5Gc due to ancient mutations fixed over 30 million years ago in these lineages (4-6). The loss of function of the CMAH enzyme prevents the modification of the precursor monosaccharide to the derived sialic acid Neu5Gc (in their respective sugar-nucleotide form, CMP-Neu5Ac and CMP-Neu5Gc). As illustrated in Figure 1, the lack of this enzymatic function can lead to drastic changes in the molecular composition of the glycocalyx of cells throughout the body. Recent evidence has shown that humans are not alone in this loss, instead several other species of mammals have independently fixed different loss-of-function mutations of their Cmah gene at various time depths during evolution, leading to loss of Neu5Gc in entire lineages or just individual species (6). These losses have occurred through exon deletion, premature stop codons, or frameshift mutations in the gene encoding the CMAH enzyme (4-6). The picture emerging is that of a phylogeny of mammals punctuated with taxa that have lost the capacity to synthesize Neu5Gc (Figure 2). These taxa include New World primates ( $>100$ species of South and Central American primates known as Platyrrhynes), Mustelidae (57 species of small carnivores including ferrets, martens and weasels), pinnipeds (33 species comprising seals, sea-lions and walruses), Procyonidae ( $\sim 15$ species including racoons, ringtails and coatis,) hedgehogs (17 species), bats from at least two different lineages, sperm whale (a single species), and white-tailed

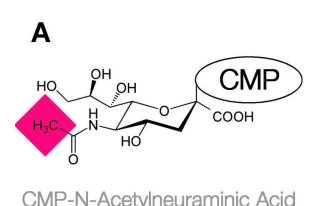

CMP-N-Acetylneuraminic Acid CMP-Neu5Ac

B

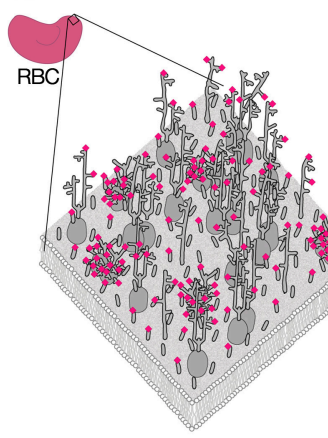

RBC from human, New World primate mustelid or pinniped

\section{CMAH}

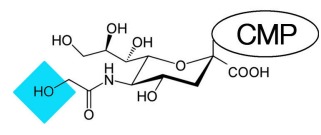

CMAH Enzyme

CMP-N-Glycoylneuraminic Acid

CMP-Neu5Gc

C

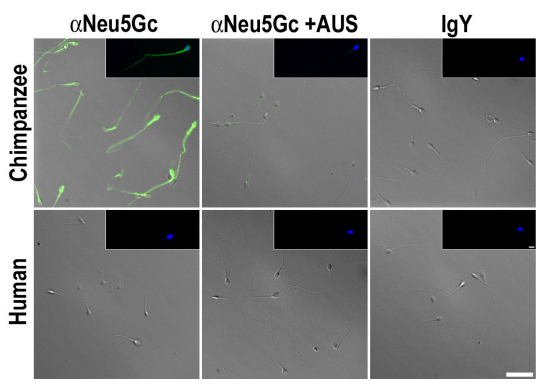

FIGURE 1 | Modification of CMP-Neu5Ac to CMP-Neu5Gc. (A) The enzyme CMAH, encoded by a single gene in all mammals, catalyzes the derivatization of Neu5Ac to Neu5Gc in the form of their sugar nucleotides, cytidine monophosphate (CMP). (B) Due to the large number of sialic acids terminating many of the glycan chains on the glycocalyces of most cells, the loss of function of the CMAH gene leads to a drastic change in the molecular identity or "flavor" of the glycocalyx, as indicated by a small fraction of a red blood cell membrane, redrawn and modified from Viitala and Järnefelt (7). (C) Micrographs showing green immunofluorescent staining of Neu5Gc on chimpanzee but not human sperm cells stained with affinity purified chicken anti-Neu5Gc lgY antibody and fluorescent secondary, controls include sialidase treated or anti-lgY secondary antibody alone, nuclei stained by DAPI (blue) reprinted from Ghaderi et al. (8) with permission. 


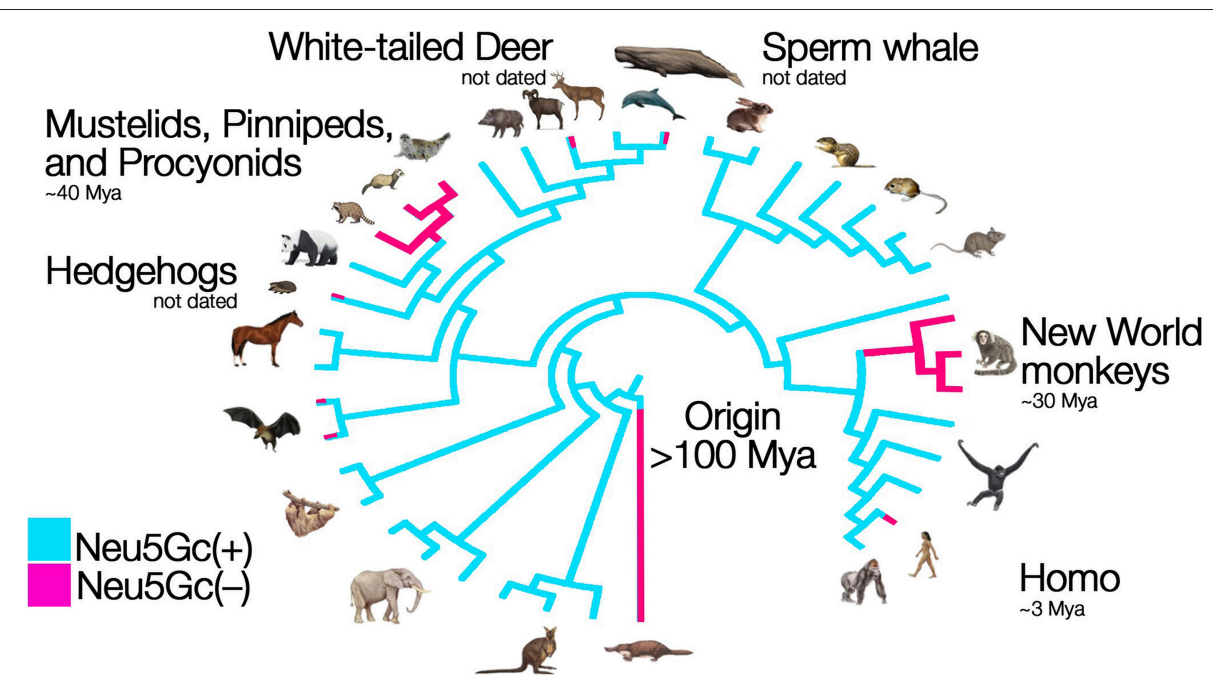

FIGURE 2 | Parallel evolution and loss of an innate self-signal. Humans cannot synthesize Neu5Gc, because human CMAH was inactivated over two million years ago (red). The inactivating mutation apparently fixed rapidly after originating, which suggests that the loss could have been adaptive-driven by pathogen avoidance, reproductive conflict, or a combination of the two. Independent losses of Cmah function have recently been found in New World Primates, Mustelids and several other groups. Figure modified from Springer and Gagneux (9). In some lineages, such as bats and toothed whales, only certain species lost the capacity to make Neu5Gc (indicated by lines that are both blue and red).

deer (a single species) (4-6). For most of these groups, only a few representative taxa and a few individuals have been studied at the genomic level, and so there is the possibility that the Cmah gene remained intact or polymorphic in some of the taxa.

An obvious prediction is that additional taxa with inactivated Cmah genes will be discovered as additional complete genome sequences are obtained. These cases of convergent molecular evolution result in an overall reconfiguration of the outermost layer of the glycocalyx, now lacking Neu5Gc and carrying an excess of Neu5Ac, given that human and non-human cells retain comparable levels of sialic acid (10) (see Figure 1B for red blood cells and Figure 1C for sperm cells). Among the many functions of the glycocalyx, molecular identity is paramount (11-13). The molecular patterns, as defined by composition and structure of the glycocalyx have evolved into self-associated molecular patterns (SAMPs) (14), that contribute to efficient surveillance by innate immune receptors including complement factor $\mathrm{H}$ and Siglecs, which can inhibit immune response upon engagement with SAMPs $(14,15)$. Losing Neu5Gc would dramatically alter self-recognition. This would have required evolving altered receptor specificities, affinities, and knock-on effects in signaling pathways due to altered engagement of innate receptors. The biochemical impact of the altered sialome on the human glycocalyx could have had many other effects, including changes in inflammation and metabolism $(16,17)$.

Another potential consequence are autoreactive antibodies produced against the lost sialic acid. Indeed, despite the absence of endogenous Neu5Gc, experimental studies in humans and in $\mathrm{Cmah}^{(-/-)}$mice have revealed that dietary Neu5Gc, in both free and glycoconjugate-bound forms, can become incorporated into tissues in trace amounts. This incorporation occurs especially in tissues with rapid growth and/or turnover rates, including epithelia, endothelia, fetal tissues, and carcinomas (18-20). It has also been established that all humans have various levels of circulating antibodies specific for glycans carrying this foreign molecule, essentially making Neu5Gc a "xeno-autoantigen," which can cause "xenosialitis," an inflammation due to reaction against a xeno-sialic acid that is now part of "self" molecules (21-24). Surprisingly, even humans on diets extremely rich in Neu5Gc do not appear to accumulate beyond trace levels of this dietary xenoglycan.

How ingested Neu5Gc becomes incorporated into the human body remains incompletely understood. There is evidence that Neu5Gc is converted to GalNGc and can then be incorporated into the glycosaminoglycan chondroitin sulfate, an important component of extra-cellular matrices and skeletal bone (25). This incorporation has recently allowed the identification of GalNGc in bones and in fossilized bones as old as 3 million years, opening the possibility to study ancient glycomes of extinct hominins (26). There is much ongoing research to understand the potential effects of incorporation of dietary xenosialic acid and targeting antibodies against xeno-sialic acid, xenosialitis in the context of cancer and autoimmunity and even unexplained infertility, where chronic immune reactions to incorporated xenoglycans could contribute to xenosialitis (22-24, 27-29). Aside from humans, natural levels of antiNeu5Gc antibodies in other species lacking Neu5Gc have not been studied to date. However, anti-Neu5Gc antibodies have been seen in chickens, where antibodies can be efficiently generated upon immunization (18) and are the basis of immune assays for the detection of Neu5Gc in human samples (30). 


\section{NATURAL IMMUNIZATION AGAINST NEU5GC-GLYCANS}

There are four main differences between immunization against Neu5Gc and other xenoglycans, such as the disaccharide alphaGal, or alloglycans such as $\mathrm{ABO}$ oligosaccharide antigens. First, in the case of other xenoglycans, immunization against the missing, terminal "self"-glycan is thought to be caused by encounters with microbial glycans with the same structure (31, 32). Considering that the synthesis of endogenous Neu5Gc has never been documented for any microbe, it would appear unlikely that this microbial priming method occurs for Neu5Gc $(33,34)$. Despite the apparent lack of Neu5Gc synthetic capacity in microbes, however, at least one microbe, Nontypeable Haemophilus influenzae (NTHi), can scavenge dietary Neu5Gc and incorporate it into its own glycolipids. There is evidence that young human infants are "xeno-autoimmunized" against Neu5Gc by early $H$. influenzae infection and this method has also been utilized for experimental immunization of $\mathrm{Cmah}^{(-/-)}$mice in the laboratory (35). Immunization thus seems to depend on diets rich in Neu5Gc from red meats or certain marine sources (fish eggs or echinoderms $(27,36)$. Secondly, unlike other xenoglycans, it is important to stress that the monosaccharide Neu5Gc itself is immunogenic, none of the constituent monosaccharides of alpha-Gal (galactose) or $\mathrm{ABO}$ antigens (fucose, galactose, N-Acetylgalactosamine, and $\mathrm{N}$-Acetylglucosamine) are foreign to individuals lacking these structures and once ingested, they are incorporated as nonantigenic glycans or metabolized (37). The antigenicity of other xenoglycans, is largely determined by glycosidic linkages, rather than by the nature of the monosaccharide: galactose-alpha-1,3galactose for alpha-Gal; fucose-alpha-1,2-galactose for the $\mathrm{H}$ antigen; $\mathrm{H}$ antigen with $\mathrm{N}$-Acetylgalactosamine for $\mathrm{A}$ antigen; or $\mathrm{H}$ antigen with alpha-1,3-galactose for $\mathrm{B}$ antigen. Thirdly, unlike the other immunogenic glycans, Neu5Gc can be part of numerous different antigens depending on the identity of the sialoglycoconjugate they occur on. Finally, sialic acids are one to several orders of magnitude more abundant than either alpha-Gal or $\mathrm{ABO}$ glycans $(38,39)$. These three differences: dietary origin, antigenicity of the monomer itself, and ubiquity/abundance on the cell surface make Neu5Gc a unique antigen, whose loss may lead to wide-ranging physiological effects $(37,38)$.

While humans have many dietary sources for Neu5Gc, among the New World primates, there are very few species that eat vertebrate meat. Capuchin monkeys (genera Cebus and Sapajou) are known to prey on young coati (40), relatives of racoons belonging to the family of Procyonidae, and on lizards or birds, but these prey species all lack endogenous Neu5Gc $(5,41)$. It is thus very unlikely that these New World primates are immunized against Neu5Gc in the wild, but captive capuchin monkeys may be exposed to Neu5Gc through monkey chow containing red meat (Primate Info Net, University of Wisconsin). Hedgehogs and other insectivores, consume mostly insect prey that lack sialic acids and thus can be safely expected not to be naturally immunized against Neu5Gc (6). The same can be said for the different bat species that lack Neu5Gc, as these all feed on insects, fruit, or nectar (42). Pinnipeds (seals, sea-lions and walruses) are all strict carnivores and some of their prey include fish and marine invertebrates that could contain Neu5Gc (43). Studies of pinniped immune responses to sialic acids are urgently needed. The one species of whale also lacking Neu5Gc is the sperm whale (Physeter catodon) (6), whose diet consists mostly of giant squid and other cephalopods (squid and octopus) with occasional fish (44). Again, such a diet is unlikely to expose sperm whales to large amounts of Neu5Gc (45), leading to the prediction that they will not have circulating antibodies against the xenoglycan. Mustelids are the one group of species for which it can be assumed that dietary exposure and immunization occurs, as they are all known to feed on a variety of small mammals and vertebrates (46).

\section{EVOLUTIONARY MECHANISMS FOR THE FIXATION OF LOSS-OF-FUNCTION MUTATION}

The loss-of-function mutations of the Cmah gene are by definition recessive, as one copy of the functional gene suffices to generate a Neu5Gc positive phenotype in a diploid organism.

\section{Balancing Selection Maintaining Polymorphisms}

Some animals, including several $\mathrm{dog}$ and cat breeds, are polymorphic for Neu5Gc expression. While overall tissue expression is thought to be low, expression on blood cells in these animals can be high $(47,48)$. Polymorphisms involving Neu5Gc on the ganglioside GD3 exist in felids and are called $\mathrm{AB}$ blood groups in domestic cats (not related to primate $\mathrm{ABO}$ blood groups), where cats lacking Neu5Gc-GD3 have circulating antibodies specific for Neu5Gc (47). Dog breeds also differ in their expression of Neu5Gc on red blood cell glycolipids (48).

Due to the recessive nature of loss of function mutations, their increase in frequency within a population must be mediated by selection on homozygous carriers, who have fitness advantages conferring higher survival and/or reproductive success. For example, selection for polymorphisms involving a loss-offunction mutation could be based on the accompanying ablation of the glycan used as a receptor by pathogens (49-52).

Examples of Neu5Gc specific pathogens abound including the protozoan malaria parasite $P$. reichenowi (53), the swine pathogen E. coli $K 99$ (54) and the macaque monkey virus SV40 (55).

In contrast a number of human-specific pathogens evolved specificity for Neu5Ac, including the causative agent of human malignant malaria $P$. falciparum, the toxins of cholera agent $V$. cholerae (56) and typhoid fever agent S. typhi (57), and most influenza A viruses (58). Loss-of-function mutations, especially in polymorphic populations, could also provide partial protection from enveloped viruses that bear the antigenic glycan acquired from the cell membrane of the previous, Neu5Gc positive host. The latter mechanism would be analogous to such protection in alpha-Gal negative Old World primates (59-61) and across $\mathrm{ABO}$ mismatched humans (62-65). Such protective mechanisms are thus observed both, between species and within species with existing (balanced) 
polymorphisms. Balanced polymorphisms are maintained by frequency-dependent selection, i.e., selection favoring the rare variants, thus preventing their extinction but also preventing their fixation (see Figure 3) (66). Such dynamic co-evolutionary processes between pathogens and their hosts are the inspiration behind the terms evolutionary arms race and Red-Queen effects $(15,67)$.

Fixation of the loss-of-function allele, on the other hand, could happen either via directional selection or genetic drift, where small founder populations consist mostly of homozygous carriers of the loss-of-function mutation. First defined using plants in 1962 (68) and recently applied to primates by Galili (65), the idea of "catastrophic selection" combines these ideas with very strong selection. It is not clear how such "catastrophic selection" differs from short episodes of strong selection, possibly accompanied by demographic bottlenecks, which could also result in the fixation of loss-of-function mutations. Alternatively, selective pressure for Cmah loss-of-function could occur through reproductive conflict as discussed below.

\section{Female Immune-Mediated Selection Against Paternal Neu5Gc}

Mammalian sperm are highly sialylated as a mechanism to enhance sperm survival and function along the perilous journey through the female reproductive tract to the site of fertilization in the oviduct (69-71). Mammals make anti-sperm antibodies when directly exposed to sperm (72). Major human sperm antigens include, highly sialylated GPI-anchored glycoproteins such as CD52 $(73,74)$, which in males that have a functional $C M A H$

\section{A Maintenance of Glycan Polymorphism}

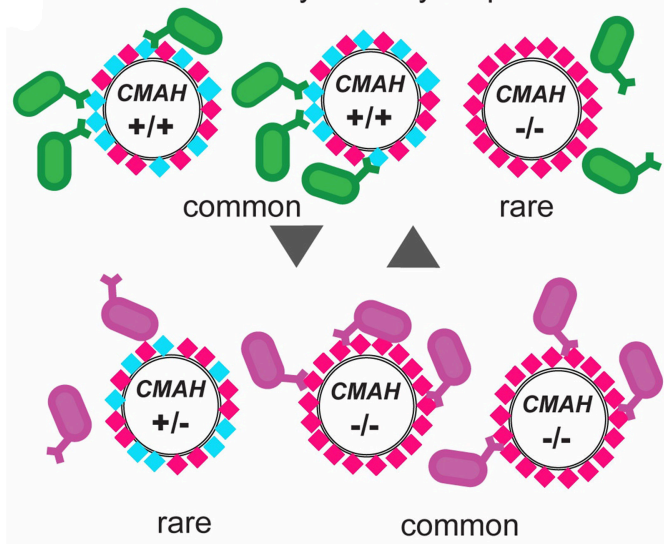

B Female immunity favors loss-of-function

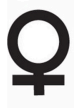

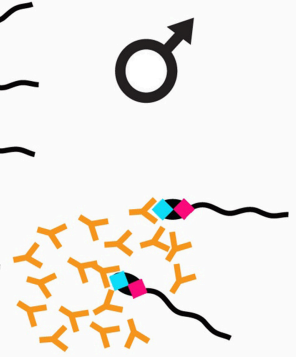

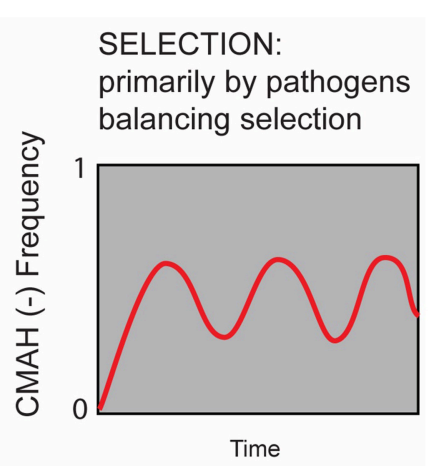

SELECTION: pathogens then sex directional selection

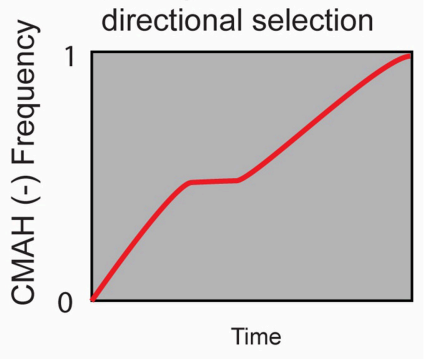

FIGURE 3 | Schematic of the interplay of natural and sexual selection acting on cell-surface sialic acids. (A) Natural selection by pathogens recognizing and exploiting Neu5Gc (blue diamond) as a receptor on host target cells can select for mutant $C M A H^{(-)}$alleles that abolish expression of Neu5Gc in homozygote individuals and prevent infection. Such homozygous null individuals have only Neu5Ac on their cells (red diamonds) and at higher frequencies would be targeted by other pathogens adapted or adapting to the host glycan change (magenta). This equilibrium would result in maintenance of glycan polymorphism by balancing selection. (B) Anti-Neu5Gc antibody-expressing $\mathrm{CMAH}^{(-/-)}$females, immunized by dietary consumption of Neu5Gc rich food (red meat) or by sperm antigens containing Neu5Gc, favor loss-of-function alleles on sperm due to reproductive incompatibility with $\mathrm{CMAH}^{(-/+)}$or $\mathrm{CMAH}^{(+/+)}$males expressing Neu5Gc on their sperm. Once the frequency of the $\mathrm{CMAH}^{(-)}$allele reaches a certain level, this process can drive the fixation of the $\mathrm{CMAH^{(-) }}$ allele in a population via directional selection. Figure modified from Ghaderi et al. (8). 
allele, carry Neu5Gc (75). Theoretically, immunization of females homozygous for the loss-of-function allele of $\mathrm{Cmah}$ could occur via insemination by males that have Neu5Gc-bearing sperm. Indeed, we have shown experimentally, using $\mathrm{Cmah}^{(-/-)}$mice immunized against $\mathrm{Neu} 5 \mathrm{Gc}$, that their immune response against Neu5Gc bearing sperm severely reduces female fertility (8). In a further study, we demonstrated that Neu5Gc bearing sperm, both, sperm from either wild type mice or from $\mathrm{Cmah}^{(-/-)}$mice exposed to seminal fluid from wildtype mice containing Neu5Gcrich $C D 52$, are both targeted by antibodies and are increasingly phagocytosed by female uterine immune cells (75). These insights have potential relevance for human fertility where Neu5Gc or
anti-Neu5Gc antibodies in the reproductive tract are common among infertility patients, but not healthy controls (29).

In addition to blocking fertilization, it is possible that antiNeu5Gc immunity from a primed $C M A H^{(-/-)}$mother (29) could also negatively affect a $C M A H^{(+/-)}$embryo or fetus in a manner similar to hemolytic diseases of the newborn caused by $\mathrm{ABO}$ glycan mismatches.

Reproductive xenosialitis could thus be a plausible mechanism mediating directional selection, leading to the fixation of the loss-of-function allele in the population, irrespective of the mechanism(s) involved for the initial selection favoring the mutation (see Figure 4).

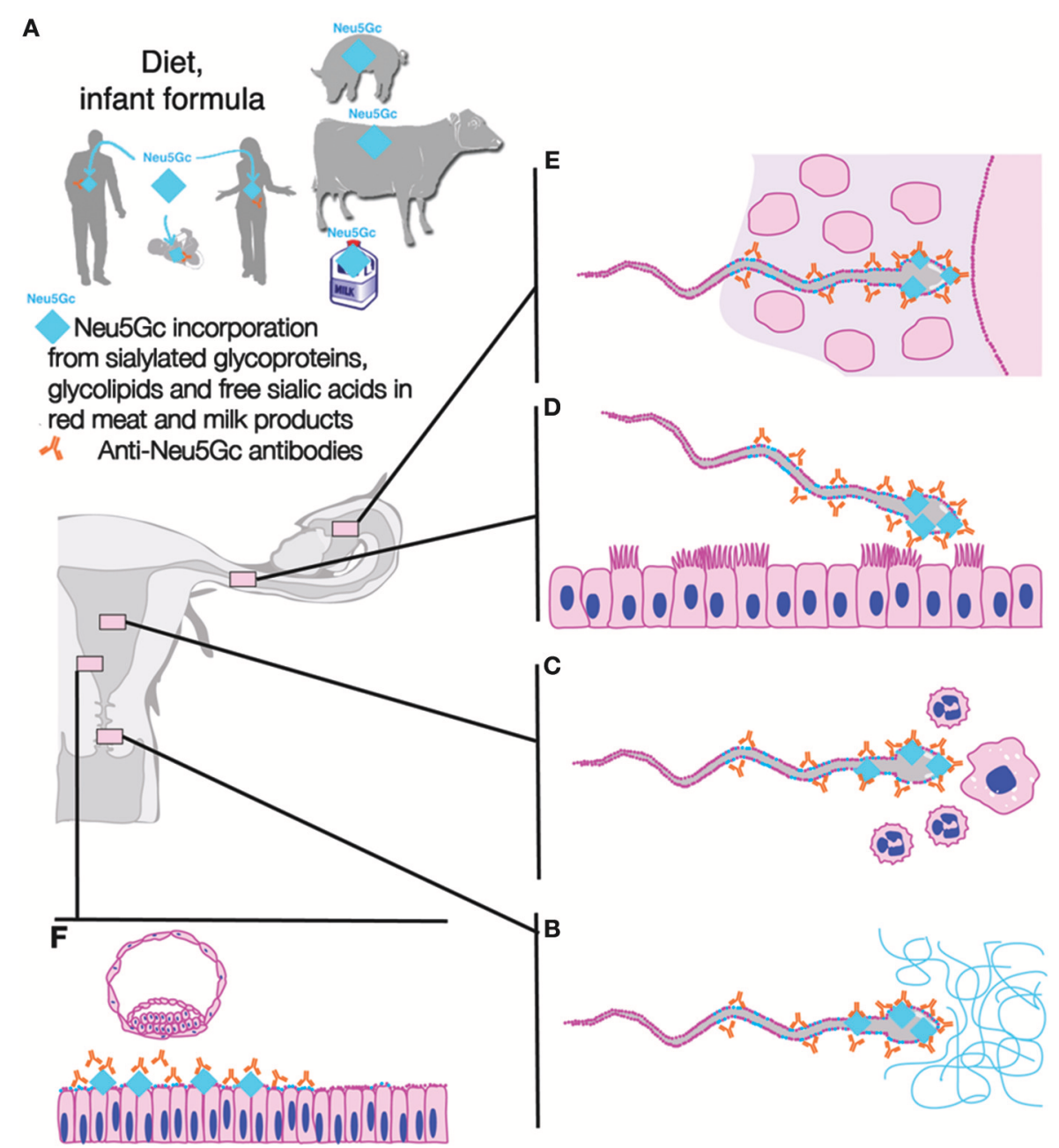

FIGURE 4 | Exogenous (dietary) Neu5Gc and anti-Neu5Gc antibody as contributing factors to unexplained human infertility. The combination of incorporated dietary xenoglycan Neu5Gc (even in trace amounts) from red meat and milk products including cow milk-based infant formula and anti-Neu5Gc antibodies in males or females (A) could have deleterious consequences on human fertility via a number of potentially additive mechanisms which include: (B) coating of sperm by male and/or female anti-Neu5Gc antibodies, interference with sperm function, including passage through cervical mucins and/or other restrictive parts of the female reproductive tract such as the utero-tubal junction, (C) increased sperm death via female cellular and humoral immunity, where most sperm are killed by female immunity, (D) interference with sperm capacitation when sperm membranes get dynamically reconfigured, (E) interference with sperm penetration of vestment, interference with sperm-egg interactions, (F) interference with endometrial decidualization and receptivity resulting in reduced success of implantation. Figure modified from Ma et al. (75) with permission. 


\section{CONCLUSIONS AND PERSPECTIVES}

It is interesting that watershed events, such as the loss of Neu5Gc from the glycocalyx of human cells have occurred numerous times in many mammalian and other vertebrate species. These cases of convergent evolution represent precious opportunities for increased understanding of evolutionary processes. In some respects, Neu5Gc is an ideal self-molecule as it is "private" to vertebrates and, based on current data, has yet to be successfully mimicked by microbes. Against the background of this benefit, the loss of Neu5Gc appears paradoxical and may implicate strong selective regimes, either catastrophically caused by pathogens, or under directional sexual selection via female immunity to paternal xenoglycans. Massive genetic drift, or combinations of milder selection and founder events, can also not be excluded.

More information on species expected to encounter Neu5Gc in their diets, i.e., mustelids, pinnipeds, and humans, is needed to begin answering several outstanding questions in the field: For instance, what are the potential protective functions of anti-Neu5Gc antibodies in species that lack this sialic acid, especially as regards ongoing protection from cross-species

\section{REFERENCES}

1. Varki A, Schnaar RL, Schauer, R. Sialic acids and other nonulosonic acids. In: Varki A, Cummings RD, Esko JD, Stanley P, Hart GW, Aebi M, Darvill AG, et al. eds. Essentials of Glycobiology. Cold Spring Harbor, NY: Cold Spring Harbor Laboratory Press (2015). p. 179-95.

2. Chou HH, Takematsu H, Diaz S, Iber J, Nickerson E, Wright KL et al. A mutation in human CMP-sialic acid hydroxylase occurred after the Homo-Pan divergence. Proc Natl Acad Sci USA. (1998) 95:11751-6. doi: 10.1073/pnas.95.20.11751

3. Chou HH, Hayakawa T, Diaz S, Krings M, Indriati E, Leakey M, et al. Inactivation of CMP-N-acetylneuraminic acid hydroxylase occurred prior to brain expansion during human evolution. Proc Natl Acad Sci USA. (2002) 99:11736-41. doi: 10.1073/pnas.182257399

4. Springer SA, Diaz SL, Gagneux, P. Parallel evolution of a self-signal: humans and new world monkeys independently lost the cell surface sugar Neu5Gc. Immunogenetics. (2014) 66:671-4. doi: 10.1007/s00251-014-0795-0

5. Ng PS, Bohm R, Hartley-Tassell LE, Steen JA, Wang H, Lukowski SW, et al. Ferrets exclusively synthesize Neu5Ac and express naturally humanized influenza A virus receptors. Nat Commun. (2014) 5:5750. doi: $10.1038 /$ ncomms6750

6. Peri S, Kulkarni A, Feyertag F, Berninsone PM, Alvarez-Ponce D. Phylogenetic distribution of CMP-Neu5Ac Hydroxylase (CMAH), the enzyme synthetizing the proinflammatory human xenoantigen Neu5Gc. Genome Biol Evol. (2018) 10:207-19. doi: 10.1093/gbe/evx251

7. Viitala, J, Järnefelt, J. The red cell surface revisisted. TIBS. (1985) 392-395.

8. Ghaderi D, Springer SA, Ma F, Cohen M, Secrest P, Taylor RE, et al. Sexual selection by female immunity against paternal antigens can fix loss of function alleles. Proc Natl Acad Sci USA. (2011) 108:17743-8. doi: 10.1073/pnas.1102302108

9. Springer SA, Gagneux P. Glycomics: revealing the dynamic ecology and evolution of sugar molecules. J Proteomics. (2016) 135:90-100. doi: 10.1016/j.jprot.2015.11.022

10. Varki A. Colloquium paper: uniquely human evolution of sialic acid genetics and biology. Proc Natl Acad Sci USA. (2010) 107 (Suppl. 2):8939-46. doi: 10.1073/pnas.0914634107

11. Gagneux P, Varki A. Evolutionary considerations in relating oligosaccharide diversity to biological function. Glycobiology. (1999) 9:747-55. doi: $10.1093 /$ glycob/9.8.747 infections by enveloped viruses bearing Neu5Gc on their viral envelopes? Or on the flip-side, what are the potential liabilities of anti-Neu5Gc antibodies due to autoimmunity against incorporated dietary Neu5Gc? Evolutionary events such as the ones discussed here exemplify how glycans, rather than representing the end result of different evolutionary histories and contingencies, can become an evolutionary force of their own and constrain future evolution of entire lineages including subsequent compensatory evolution of glycan binding immune receptors $(15,76)$.

\section{AUTHOR CONTRIBUTIONS}

MA and PG did the research and wrote the paper. PG produced the figures.

\section{FUNDING}

Mathers Charitable Foundation, Mizutani Foundation for Glycosciences, Grant 170174.
12. Varki A, Gagneux P. Multifarious roles of sialic acids in immunity. Ann N Y Acad Sci. (2012) 1253:16-36. doi: 10.1111/j.1749-6632.2012.06517.x

13. Varki A, Gagneux P. Biological functions of glycans. In: Varki A, Cummings RD, Esko JD, Stanley P, Hart GW, Aebi M, et al. eds. Essentials of Glycobiology. Cold Spring Harbor, NY: Cold Spring Harbor Laboratory Press (2015). p. $77-88$.

14. Varki A. Since there are PAMPs and DAMPs, there must be SAMPs? Glycan "self-associated molecular patterns" dampen innate immunity, but pathogens can mimic them. Glycobiology. (2011) 21:1121-4. doi: 10.1093/glycob/cwr087

15. Angata T. Possible influences of endogenous and exogenous ligands on the evolution of human siglecs. Front Immunol. (2018) 9:2885. doi: $10.3389 /$ fimmu.2018.02885

16. Okerblom JJ, Schwarz F, Olson J, Fletes W, Ali SR, Martin PT, et al. Loss of CMAH during human evolution primed the monocyte-macrophage lineage toward a more inflammatory and phagocytic state. J Immunol. (2017) 198:2366-73. doi: 10.4049/jimmunol.1601471

17. Okerblom J, Fletes W, Patel HH, Schenk S, Varki A, Breen EC. Humanlike $\mathrm{Cmah}$ inactivation in mice increases running endurance and decreases muscle fatigability: implications for human evolution. Proc Biol Sci. (2018) 285: 20181656. doi: 10.1098/rspb.2018.1656

18. Tangvoranuntakul P, Gagneux P, Diaz S, Bardor M, Varki N, Varki A, et al. Human uptake and incorporation of an immunogenic nonhuman dietary sialic acid. Proc Natl Acad Sci USA. (2003). 108:17743-8. doi: $10.1073 /$ pnas.2131556100

19. Bardor M, Nguyen DH, Diaz S, Varki, A. Mechanism of uptake and incorporation of the non-human sialic acid N-glycolylneuraminic acid into human cells. J Biol Chem. (2005) 280:4228-37. doi: 10.1074/jbc.M412040200

20. Nguyen DH, Tangvoranuntakul P, Varki A. Effects of natural human antibodies against a nonhuman sialic acid that metabolically incorporates into activated and malignant immune cells. J Immunol. (2005) 175:228-36. doi: 10.4049/jimmunol.175.1.228

21. Padler-Karavani V, Yu H, Cao H, Chokhawala H, Karp F, Varki N, et al. Diversity in specificity, abundance, and composition of anti-Neu5Gc antibodies in normal humans: potential implications for disease. Glycobiology. (2008) 18:818-30. doi: 10.1093/glycob/cwn072

22. Pham T, Gregg CJ, Karp F, Chow R, Padler-Karavani V, Cao H, et al. Evidence for a novel human-specific xeno-auto-antibody response against vascular endothelium. Blood. (2009) 114:5225-35. doi: 10.1182/blood-2009-0 $5-220400$ 
23. Samraj AN, Bertrand KA, Luben R, Khedri Z, Yu H, Nguyen D, et al. Polyclonal human antibodies against glycans bearing red meatderived non-human sialic acid $\mathrm{N}$-glycolylneuraminic acid are stable, reproducible, complex and vary between individuals: total antibody levels are associated with colorectal cancer risk. PLoS ONE. (2018) 13:e0197464. doi: 10.1371/journal.pone.0197464

24. Hedlund M, Padler-Karavani V, Varki NM, Varki, A. Evidence for a human-specific mechanism for diet and antibody-mediated inflammation in carcinoma progression. Proc Natl Acad Sci USA. (2008) 105:18936-41. doi: 10.1073/pnas.0803943105

25. Bergfeld AK, Pearce OM, Diaz SL, Lawrence R, Vocadlo DJ, Choudhury $\mathrm{B}$, et al. Metabolism of vertebrate amino sugars with $\mathrm{N}$-glycolyl groups: incorporation of $\mathrm{N}$-glycolylhexosamines into mammalian glycans by feeding N-glycolylgalactosamine. J Biol Chem. (2012) 287:28898-916. doi: 10.1074/jbc.M112.363499

26. Bergfeld AK, Lawrence R, Diaz SL, Pearce OMT, Ghaderi D, Gagneux P, et al. Proc Natl Acad Sci USA. (2017) 114:E8155-64. doi: 10.1073/pnas.1706306114

27. Samraj AN, Pearce OM, Laubli H, Crittenden AN, Bergfeld AK, Banda K, et al. A red meat-derived glycan promotes inflammation and cancer progression. Proc Natl Acad Sci USA. (2015) 112:542-7. doi: 10.1073/pnas.1417508112

28. Alisson-Silva F, Kawanishi K, Varki A. Human risk of diseases associated with red meat intake: analysis of current theories and proposed role for metabolic incorporation of a non-human sialic acid. Mol Aspects Med. (2016) 51:16-30. doi: 10.1016/j.mam.2016.07.002

29. Sroga JL, Wu D, Ma F, Tecle E, Reynoso HS, Ressler IB, et al. Detection of the dietary xenoglycan N-glycolylneuraminic acid (Neu5Gc) and anti-Neu5Gc antibodies within reproductive tracts of male and female infertility subjects. Clin Obstet Gynecol Reprod. (2015) 1:72-8. doi: 10.15761/COGRM.1000120

30. Diaz SL, Padler-Karavani V, Ghaderi D, Hurtado-Ziola N, Yu H, Chen X, et al. Sensitive and specific detection of the non-human sialic Acid Nglycolylneuraminic acid in human tissues and biotherapeutic products. PLoS ONE. (2009) 4:e4241. doi: 10.1371/journal.pone.0004241

31. Springer GF, Horton RE. Blood group isoantibody stimulation in man by feeding blood group-active bacteria. J Clin Invest. (1969) 48:1280-91. doi: 10.1172/JCI106094

32. Parker W, Yu PB, Holzknecht ZE, Lundberg K, Buckley RH, Platt JL. Specificity and function of "natural" antibodies in immunodeficient subjects: clues to B cell lineage and development. J Clin Immunol. (1997) 17:311-21. doi: 10.1023/A:1027378716015

33. Adibekian A, Stallforth P, Hecht M, Werz DB, Gagneux P, Seeberger $\mathrm{PH}$. Comparative bioinformatics analysis of the mammalian and bacterial glycomes. Chem Sci. (2011) 2:337-344. doi: 10.1039/C0SC00322K

34. Varki A. Multiple changes in sialic acid biology during human evolution. Glycoconj J. (2009) 26:231-45. doi: 10.1007/s10719-008-9183-Z

35. Taylor RE, Gregg CJ, Padler-Karavani V, Ghaderi D, Yu H, Huang S, et al. Novel mechanism for the generation of human xeno-autoantibodies against the nonhuman sialic acid N-glycolylneuraminic acid. J Exp Med. (2010) 207:1637-46. doi: 10.1084/jem.20100575

36. Yeşilyurt B, Sahar U, Deveci R. Determination of the type and quantity of sialic acid in the egg jelly coat of the sea urchin Paracentrotus lividus using capillary LC-ESI-MS/MS. Mol Reprod Dev. (2015) 82:115-22. doi: 10.1002/mrd.22448

37. Stanley P, Cummings RD. Structures common to different glycans. In: Varki A, Cummings RD, Esko JD, Stanley P, Hart GW, Aebi M, et al. eds. Essentials of Glycobiology. Cold Spring Harbor, NY: Cold Spring Harbor Laboratory Press (2015). p. 99-112.

38. Collins BE, Blixt O, DeSieno AR, Bovin N, Marth JD, Paulson JC. Masking of CD22 by cis ligands does not prevent redistribution of CD22 to sites of cell contact. Proc Natl Acad Sci USA. (2004) 101:6104-9. doi: 10.1073/pnas.0400851101

39. Galili U, Tibell A, Samuelsson B, Rydberg L, Groth CG. Increased anti-Gal activity in diabetic patients transplanted with fetal porcine islet cell clusters. Transplantation. (1995) 59:1549-56. doi: 10.1097/00007890-199506150-00008

40. Fedigan LM. Vertebrate predation in Cebus capucinus: meat eating in a neotropical monkey. Folia Primatol. (1990) 54:196-205. doi: 10.1159/000156444

41. Schauer R, Srinivasan GV, Coddeville B, Zanetta JP, Guerardel Y. Low incidence of $\mathrm{N}$-glycolylneuraminic acid in birds and reptiles and its absence in the platypus. Carbohydr Res. (2009) 344:1494-500 doi: 10.1016/j.carres.2009.05.020

42. Springer MS. Phylogenetics: bats united, microbats divided. Curr Biol. (2013) 23:R999-1001. doi: 10.1016/j.cub.2013.09.053

43. Tollit DJ, Schulze AD, Trites AW, Olesiuk PF, Crockford SJ, Gelatt TS, et al. Development and Application of DNA Techniques for Validating and Improving Pinniped Diet Estimates. Ecol Appl. (2009) 19:889-905. doi: 10.1890/07-1701.1

44. Clarke MR, Martins HR, Pascoe P. The diet of sperm whales (Physeter macrocephalus Linnaeus 1758) off the Azores. Philos Trans R Soc Lond B Biol Sci. (1993) 339:67-82. doi: 10.1098/rstb.1993.0005

45. Schauer R, Kamerling JP. Exploration of the Sialic Acid World. Adv Carbohydr Chem Biochem. (2018) 75:1-213. doi: 10.1016/bs.accb.2018.09.001

46. Dragoo JW, Honeycutt RL. Systematics of Mustelid-Like Carnivores. J Mammal. (1997) 426-443.

47. Bighignoli B, Niini T, Grahn RA, Pedersen NC, Millon LV, Polli M, et al. Cytidine monophospho- $\mathrm{N}$-acetylneuraminic acid hydroxylase (CMAH) mutations associated with the domestic cat $\mathrm{AB}$ blood group. BMC Genet. (2007) 8:27. doi: 10.1186/1471-2156-8-27

48. Yasue S, Handa S, Miyagawa S, Inoue J, Hasegawa A, Yamakawa T. Difference in form of sialic acid in red blood cell glycolipids of different breeds of dogs. J Biochem. (1978) 83:1101-7. doi: 10.1093/oxfordjournals.jbchem. a131999

49. Huang P, Farkas T, Zhong W, Tan M, Thornton S, Morrow AL, et al. Norovirus and histo-blood group antigens: demonstration of a wide spectrum of strain specificities and classification of two major binding groups among multiple binding patterns. J Virol. (2005) 79:6714-22. doi: 10.1128/JVI.79.11.6714-6722.2005

50. Tan M, Jiang X. Norovirus and its histo-blood group antigen receptors: an answer to a historical puzzle. Trends Microbiol. (2005) 13:285-93. doi: 10.1016/j.tim.2005.04.004

51. Zakhour M, Ruvoen-Clouet N, Charpilienne A, Langpap B, Poncet $\mathrm{D}$, Peters T, et al. The alphaGal epitope of the histo-blood group antigen family is a ligand for bovine norovirus Newbury2 expected to prevent cross-species transmission. PLoS Pathog. (2009) 5:e1000504. doi: 10.1371/journal.ppat.1000504

52. Zhang D, Huang P, Zou L, Lowary TL, Tan M, Jiang X. Tulane virus recognizes the A type 3 and B histo-blood group antigens. J Virol. (2015) 89:1419-27. doi: 10.1128/JVI.02595-14

53. Martin MJ, Rayner JC, Gagneux P, Barnwell JW, Varki A. Evolution of humanchimpanzee differences in malaria susceptibility: relationship to human genetic loss of N-glycolylneuraminic acid. Proc Natl Acad Sci USA. (2005) 102:12819-24. doi: 10.1073/pnas.0503819102

54. Smi, H, Gaastra W, Kamerling JP, Vliegenthart JF, de Graaf FK. Isolation and structural characterization of the equine erythrocyte receptor for enterotoxigenic Escherichia coli K99 fimbrial adhesin. Infect Immun. (1984) 46:578-84.

55. Campanero-Rhodes MA, Smith A, Chai W, Sonnino S, Mauri L, Childs RA, et al. N-glycolyl GM1 ganglioside as a receptor for simian virus 40. J Virol. (2007) 81:12846-58. doi: 10.1128/JVI.01311-07

56. Alisson-Silva F, Liu JZ, Diaz SL, Deng L, Gareau MG, Marchelletta R, et al. Human evolutionary loss of epithelial Neu5Gc expression and species-specific susceptibility to cholera. PLoS Pathog. (2018) 14:e1007133. doi: 10.1371/journal.ppat.1007133

57. Deng L, Song J, Gao X, Wang J, Yu H, Chen X, et al. Host adaptation of a bacterial toxin from the human pathogen Salmonella Typhi. Cell. (2014) 159:1290-9. doi: 10.1016/j.cell.2014.10.057

58. Takahashi T, Takano M, Kurebayashi Y, Masuda M, Kawagishi S, Takaguchi $\mathrm{M}$, et al. N-glycolylneuraminic acid on human epithelial cells prevents entry of influenza A viruses that possess N-glycolylneuraminic acid binding ability. J Virol. (2014) 88:8445-56. doi: 10.1128/JVI.00716-14

59. Arendrup M, Hansen JE, Clausen H, Nielsen C, Mathiesen LR, Nielsen JO. Antibody to histo-blood group A antigen neutralizes HIV produced by lymphocytes from blood group A donors but not from blood group B or O donors. AIDS. (1991) 5:441-4. doi: 10.1097/00002030-199104000-00014

60. Takeuchi Y, Porter CD, Strahan KM, Preece AF, Gustafsson K, Cosset FL, et al. Sensitization of cells and retroviruses to human serum by (alpha 1-3) galactosyltransferase. Nature. (1996) 379:85-8. doi: 10.1038/379085a0 
61. Kim NY, Jung WW, Oh YK, Chun T, Park HY, Lee HT, et al. Natural protection from zoonosis by alpha-gal epitopes on virus particles in xenotransmission. Xenotransplantation. (2007) 14:104-11. doi: 10.1111/j.1399-3089.2007.00377.x

62. Preece AF, Strahan KM, Devitt J, Yamamoto F, Gustafsson K. Expression of $\mathrm{ABO}$ or related antigenic carbohydrates on viral envelopes leads to neutralization in the presence of serum containing specific natural antibodies and complement. Blood. (2002) 99:2477-82. doi: 10.1182/blood.V99. 7.2477

63. Neil SJ, McKnight A, Gustafsson K, Weiss RA. HIV-1 incorporates $\mathrm{ABO}$ histo-blood group antigens that sensitize virions to complementmediated inactivation. Blood. (2005) 105:4693-99. doi: 10.1182/blood-200411-4267

64. Onsten TG, Callegari-Jacques SM, Goldani LZ. The higher frequency of blood group B in a brazilian population with HIV infection. Open AIDS J. (2013) 7:47-50. doi: 10.2174/1874613601307010047

65. Galili U. Evolution in primates by "Catastrophic-selection" interplay between enveloped virus epidemics, mutated genes of enzymes synthesizing carbohydrate antigens, and natural anti-carbohydrate antibodies. Am J Phys Anthropol. (2018) 168:352-63. doi: 10.1002/ajpa.23745

66. Bubb KL, Bovee D, Buckley D, Haugen E, Kibukawa M, Paddock M, et al. Scan of human genome reveals no new Loci under ancient balancing selection. Genetics. (2006) 173:2165-77. doi: 10.1534/genetics.106. 055715

67. Van Valen LM. A new evolutionary law. Evol Theory. (1973) 1:1-30.

68. Lewis, H. Catastrophic selection as a factor in speciation. Evolution. (1962) 16:257-71. doi: 10.1111/j.1558-5646.1962.tb03218.x

69. Tollner TL, Bevins CL, Cherr GN. Multifunctional glycoprotein DEFB126-a curious story of defensin-clad spermatozoa. Nat Rev Urol. (2012) 9:365-75. doi: 10.1038/nrurol.2012.109
70. Tecle E, Gagneux P. Sugar-coated sperm: unraveling the functions of the mammalian sperm glycocalyx. Mol Reprod Dev. (2015) 82:635-50. doi: $10.1002 / \mathrm{mrd} .22500$

71. Ma X, Pan Q, Feng Y, Choudhury BP, Ma Q, Gagneux P, et al. Sialylation facilitates the maturation of mammalian sperm and affects its survival in female uterus. Biol Reprod. (2016) 94:123. doi: 10.1095/biolreprod.115.137810

72. Heshmati HM, Taleb M, Turpin G. [The blood-testis barrier]. Ann Endocrinol. (1984) 45:115-7.

73. Hasegawa A, Koyama K. Antigenic epitope for sperm-immobilizing antibody detected in infertile women. J Reprod Immunol. (2005) 67:77-86. doi: 10.1016/j.jri.2005.06.005

74. Kirchhoff C. CD52 is the 'major maturation-associated' sperm membrane antigen. Mol Hum Reprod. (1996) 2:9-17. doi: 10.1093/molehr/2.1.9

75. Ma F, Deng L, Secrest P, Shi L, Zhao J, Gagneux P. A mouse model for dietary xenosialitis: antibodies to xenoglycan can reduce fertility. J Biol Chem. (2016) 291:18222-31. doi: 10.1074/jbc.M116.739169

76. Springer SA, Gagneux P. Glycan evolution in response to collaboration, conflict, and constraint. J Biol Chem. (2013) 288:6904-11. doi: 10.1074/jbc.R112.424523

Conflict of Interest Statement: The authors declare that the research was conducted in the absence of any commercial or financial relationships that could be construed as a potential conflict of interest.

Copyright (C) 2019 Altman and Gagneux. This is an open-access article distributed under the terms of the Creative Commons Attribution License (CC BY). The use, distribution or reproduction in other forums is permitted, provided the original author(s) and the copyright owner(s) are credited and that the original publication in this journal is cited, in accordance with accepted academic practice. No use, distribution or reproduction is permitted which does not comply with these terms. 